\title{
EPISTEMOLOGIA E METODOLOGIA DO TURISMO CULTURAL URBANO: O CASO DA SOCIOLOGIA Artística das CULTURAS MÓVEIS E DA COMUNICAÇÃo TURÍSTICA EM REDES SOCIAIS URBANAS
}

\author{
Pedro de Andrade
}

\begin{abstract}
Resumo
Os debates epistemológicos, teóricos e metodológicos que visam credibilidade científica não podem prescindir da correspondente aplicação ao tecido social. Inversamente, a ação deverá sempre informar a reflexão. Pretende-se neste artigo demonstrar racionalmente e mostrar sensorialmente que um dos géneros sociológicos, a Sociologia Artística, faz transbordar a Sociologia e a sua linguagem científica da academia para atividades de extensão criativas, como a exposição do saber sociológico no espaço público urbano, por exemplo no caso da galeria de arte. Do mesmo modo, o conhecimento e linguagem artísticos deverão contaminar a discussão sociológica através de uma sensibilidade inovadora. Isso é possível por intermédio da inserção, num texto sociológico, não apenas das imagens oriundas de uma exposição de arte, apresentadas enquanto Figuras $(1,2 \ldots n)$. Para além disso, a própria exposição de arte poderá ser entendida como uma configuração social e sociológica que faz parte orgânica do próprio corpo do texto sociológico tradicional. Busca-se assim uma hibridação de saberes profunda, que poderá enriquecer, mas também subverter, tanto os debates sociológicos quanto as exposições de arte. Este propósito realiza-se aqui por diversos meios interligados: uma aproximação epistemológica entre a Sociologia Artística e a Hibridologia; a problematização teórica das culturas móveis; o trabalho de campo empírico no quadro da comunicação urbana na Cidade 3.0 e a comunicação turística no contexto do Turismo 3.0; e a exposição 'New Art Fest'17, como palco da aplicação de abordagens metodológicas sociológicas e artísticas inovadoras. Numa primeira etapa, a Exposição Sociológica sobre Turismo 3.0/Cidade 3.0 demonstrou e mostrou os saberes urbanos e da viagem, no seio do espaço da galeria de arte. Numa segunda fase, este saber testado no público da exposição é reintroduzido num artigo de revista científica. Um tal duplo movimento de pesquisa hibridiza e confronta, em moldes ao mesmo tempo originários e originais, o conhecimento e a prática científicos e artísticos.
\end{abstract}

\section{Palavras-chave}

Abordagens metodológicas inovadoras; comunicação do turismo; culturas móveis; hibridologia; Sociologia Artística

\begin{abstract}
The epistemological, theoretical and methodological debates that aim at scientific credibility, cannot ignore the corresponding application to the social fabric. Conversely, action should always inform reflection. This article rationally demonstrates and sensorialy exhibits the following: one of the sociological genres, Artistic Sociology, transports sociology and its scientific language, from the academia to creative extension activities such as the exhibition of sociological knowledge within urban public space, for example in the case of the art gallery. In the same way, artistic knowledge and language should contaminate sociological discussion through an innovative sensibility. This is possible through the insertion, within a sociological text, not only of images from an art exhibition, presented as 'Figures' $(1,2 \ldots n)$. In addition, the art exhibition itself can be understood as a social and sociological configuration that is an organic part of the very
\end{abstract}


body of the traditional sociological text. Thus, a profound hybridization of knowledge is sought, which can enrich, but also subvert, both sociological debates and art exhibitions. This purpose is accomplished here by several interconnected means: an epistemological approach between Artistic Sociology and Hybridogy; the theoretical problematization of mobile cultures; the empirical field work in the context of urban communication at City 3.0 and tourism communication in the context of Tourism 3.0; and the exhibition 'New Art Fest'17, as the field for the application of innovative sociological and artistic methodological approaches. A first step was Sociological Exibition on Tourism 3.0 / Cidade 3.0, that demonstrated and showed the urban and travel knowledge, within the space of the art gallery. In a second phase, this knowledge tested through the exhibition audience, is reintroduced in a scientific journal article. Such a double research movement hybridizes and confronts, in both originary and original forms, scientific and artistic knowledge and practice.

KEYwORDS

Artistic sociology; hybridology; innovative methodological approaches; mobile cultures; tourism communication

\section{INTRODUÇÃO: METODOLOGIAS E INOVAÇÃo SOCIOLÓGICA}

Este artigo não pretende ser mais do que a apresentação de um trabalho em progresso na área científica transversal da metodologia, que hibridiza a reflexão teórica com a aplicação prática de saberes, procedimentos e utensílios, tanto aqueles clássicos quanto os experimentais. Em particular, as metodologias atuais crioulizam a natureza da ciência moderna com as potencialidades dos recursos pós-modernos ou inerentes à modernidade avançada, como os modos de fazer digitais, desde o início dos anos 9o, após a emergência das novas tecnologias interativas e da Internet. Uma destas ferramentas recentes para a investigação é o conhecimento em linha, que recebe um novo alento não apenas no interior de redes sociais como o Facebook, mas igualmente no seio das redes sociais e semânticas da Web 3.0 ou web semântica. Os sites e outros recursos da Web 3.0 distinguem-se por privilegiar a produção e a partilha de conhecimento, e não apenas de informação, como sublinha Gilbert Paquette: "como podemos tornar a Web mais útil, mais inteligente, mais intensiva em conhecimento para atender às necessidades cada vez mais exigentes de aprendizagem e trabalho?" (Paquette, 2010, p. xiii).

O presente texto trata de alguns dos meios e métodos produtores e difusores do conhecimento científico. Em particular, a reflexão epistemológico-teórica é aqui aplicada a paisagens e arenas científicas que lidam com processos híbridos e transculturais. Algumas das características destes saberes mestiços mais recentes (mas claramente não sendo os seus únicos atributos) são a sua natureza global e interativa, o que introduz novas dificuldades associadas aos eixos epistemológico, teórico, analítico e empírico, inerentes ao trabalho e à investigação científicos.

As consequências deste contexto social hodierno adivinham-se múltiplas. Uma delas é a emergência de metodologias inovadoras, no seio dos diversos modos e meios de conhecimento, como alerta Patricia Leavy (2009, p. 18), ao aproximar a pesquisa sociológica da prática artística: "trabalhar com metodologias inovadoras muitas vezes 
exige que os pesquisadores atravessem fronteiras disciplinares, deixem as suas zonas de conforto..."

Note-se que, de um ponto de vista epistemológico, uma "metodologia" não se confunde com um "método". A metodologia emerge como uma espécie de gramática dos métodos e das técnicas, ou de outras atividades procedimentais destinadas à execução de tarefas específicas, em processos de busca de um ou mais objetivos de conhecimento ou de sabedoria. Ou seja, uma metodologia constitui uma grelha de problematização, que inclui, entre outros elementos, um conjunto de reflexões epistemológicas e teóricas abrangentes, sobre os modos práticos de desenvolvimento de específicos campos de estudo ou de tipos de conhecimento. Por outras palavras, o debate epistemológico sobre as metodologias não se reduz à diferença entre métodos e técnicas, nem se confina à dissemelhança entre metodologias e abordagens metodológicas, nem se limita a qualquer outra dicotomia redutora. O panorama traduz-se numa mais intensa complexidade, e envolve estratégias e táticas muito variadas de fazer Ciência. Sumarizando apenas algumas delas, e entre outros traços, a metodologia releva da lógica ou da dialética, a abordagem metodológica revela-se processual, o método desvela-se enquanto atividade regulatória, e a técnica afirma-se enquanto ação instrumental.

Para além disso, é preciso distinguir entre as ideias e conceitos de "criação"”, "invenção" e "inovação". O primeiro termo foi mais usado em atividades artísticas e literárias, sobretudo no quadro do Romantismo. Por seu turno, a invenção associa-se, frequentemente, aos discursos científicos e técnicos da modernidade, por vezes confundindo-se, algo insatisfatoriamente, com a investigação pura ou fundamental. E a inovação significa mais propriamente a aplicação, nas atividades económicas e no tecido social, da criação e da invenção, articuladas às novas tecnologias, cada vez mais no contexto dos novos media digitais.

Assim sendo, neste artigo, o conceito "inovação" é utilizado em termos de aplicação, da criatividade e inventividade, pelos cientistas sociais, aos campos económicos, sociais, políticos e culturais da contemporaneidade. Como se verá adiante, busca-se desconstruir, mas não substituir totalmente, posturas epistemológicas e metodológicas correntes, que subscrevem uma certa atitude não crítica ou mesmo acrítica em relação aos métodos e técnicas sociológicas herdadas ou adquiridas.

Nesta ordem de ideias, torna-se relevante revisitar, embora brevemente, a equação teórico-metodológica que articula o caos, as causas e os casos.

Perante o caos emergente diariamente no seio do tecido social, a ciência moderna procurou domesticá-lo, principalmente desde o século XVI, a partir de uma linguagem e discurso racional que, entre outros procedimentos explicativos, privilegiou a pesquisa das causas dos fenómenos sociais, articuladas aos seus efeitos. Para além deste pensamento e prática causalistas, a racionalidade moderna utilizou uma reflexão e trabalho de campo casuísticos, que procurou superar as insuficiências da aproximação causal a partir de uma aproximação mais empírica e delimitada. Recentemente, a perspetiva pós-moderna ou da modernidade avançada inclui teorias como a "teoria do caos", e metodologias que procuram descodificar o próprio caos subjacente à natureza, ao homem e 
à própria cultura, entidades onde o processo de hibridação constitui não a exceção mas a regra ou uma das regularidades, modificando mesmo algumas das nossas certezas sobre a natureza da própria ciência (Gleik, 2008).

Hoje em dia, os cientistas em geral e os cientistas sociais em particular, problematizam e utilizam, cada vez mais, métodos híbridos, ou seja, aqueles que misturam, sintetizam ou crioulizam entidades ou procedimentos diversos, diferentes e até opostos. Por exemplo, numa pesquisa, o racional mescla-se com o sensível, o quantitativo é contaminado pelo qualitativo, os procedimentos "manuais" utilizam com proveito as tecnologias digitais, etc.

Estes e outros desassossegos da epistemologia e metodologia contemporâneas parecem comprovar que nenhuma metodologia se constitui perenemente por decreto científico, nem nenhum manual pode ditar aquilo que deve ser a naturalidade, a normalidade e a legitimidade do trabalho científico. Diferentemente, hoje existem metodologias simultaneamente críticas e dialógicas, que promovem encontros mas também reencontros, entre os modos e modas de produzir, interpretar e disseminar o conhecimento científico. Eis algumas ilustrações deste processo social, mas igualmente sociológico.

No que respeita aos métodos quantitativos, por exemplo, assistimos a "tempos turbulentos para a metodologia dos inquéritos" por questionário, numa conjuntura de generalização dos métodos mistos (Dillman, 2009, p. 9):

o desenvolvimento e a implementação generalizada dessas tecnologias de comunicação nos últimos anos fizeram com que os inquiridores tivessem que tomar medidas adicionais para distinguir os seus inquéritos por questionário dos inúmeros outros contatos (correio, telefonemas, e-mails, mensagens de texto, etc.) que cada um de nós recebe diariamente. Além disso, o casamento dos inquéritos com dispositivos de alta tecnologia exige que os pesquisadores forneçam considerações adicionais sobre como diferentes populações interagem com as novas tecnologias.

Quanto aos métodos qualitativos, a netnografia constitui um método que inclui um conjunto de técnicas sociológicas e etnográficas relevantes e estimulantes para os Estudos Culturais, por exemplo para a análise e interpretação da interatividade entre os membros das comunidades em linha. Por exemplo, e como sublinha Robert Kozinets (2012, pp. 68, 72), a natureza da pesquisa no terreno digital apresenta quatro caraterísticas centrais: alteração da interação; o anonimato; a acessibilidade e o arquivamento da informação pelos próprios utilizadores.

Não é de admirar, então, que as técnicas de análise de conteúdo estejam a desfrutar de um renascimento na sua aplicação à análise de conversas em linha. $\mathrm{O}$ arquivamento instantâneo das comunicações sociais presentes na esfera da Internet torna este contexto para a realização de pesquisas etnográficas muito diferente do contexto da interação face a face. (Kozinets, 2012, p. 72) 
Quanto a certas metodologias inovadoras no sentido acima explanado, ou seja, entendidas em termos de grelhas ou problemáticas de uso de métodos e técnicas originais, é sintomático o caso do design radical de jogos, um posicionamento assinado por Mary Flanagan, entre outros autores:

seja na sua capacidade de estimular a participação numa era conectada à Internet ou no seu papel como plataforma de entretenimento, intervenção, autoria e subversão, os jogos de computador - de fato, todos os jogos são altamente relevantes para a imaginação do século XXI. (Flanagan, 2009, p. 251).

Note-se ainda que a metodologia não apenas condiciona, mas é também influenciada e reconstruída pela própria natureza de cada objeto de estudos. O presente ensaio problematiza, sem facultar respostas definitivas, o terreno escorregadio das culturas móveis, em particular aquelas turísticas, operantes nas redes sociais urbanas ou digitais, que deverão ser estudadas igualmente a partir de métodos móveis. Dito de outro modo, não iremos aqui pensar nem falar de uma metodologia abstrata, única ou mesmo destinada tão-só ao ensino, mas também conversaremos sobre a confrontação desta metodologia, através de atividades de extensão, com lugares externos à academia, em terrenos móveis ou movediços do social.

De facto, como sublinha Luc Pauwels (2006, p. 120), a representação das culturas móveis pode fundar-se na expressão, multivocalidade e reflexividade veiculadas por exemplo através de filmagens realizadas no quadro de pesquisas sociológicas e antropológicas, em particular aquelas empreendidas usando tecnologias digitais: "a atual tecnologia dos média digitais permite a expansão do potencial discursivo do filme e transforma-o num produto mais híbrido, com mais possibilidades e desafios".

Por forma a ilustrar tais posturas epistemológicas e metodológicas, críticas e dialógicas, apresentaremos aqui um método híbrido, nomeado Exposição Sociológica, mostrado no interior do evento cultural New Art Fest'17, que decorreu entre 1 e 30 de Novembro de 2017, na Sala do Picadeiro do Museu Nacional História Natural e de Ciência, em Lisboa. Trata-se, como veremos abaixo, de crioulizar o conhecimento sociológico com outras linguagens e contextos sociais, como as atividades e discursos artísticos e literários. Concretamente, no seio deste método híbrido, desenvolvemos três técnicas de fazer sociologia numa galeria de arte, em diálogo estreito com os seus visitantes. Estas técnicas usaram a pretensa racionalidade científica em conexão com a alegada sensibilidade das artes. Na verdade, ambos esses modos de conhecimento utilizam, em grau maior ou menor, a razão e a sensação. $O$ autor serviu-se também de procedimentos sociológicos mais tradicionais, como a observação direta e entrevistas, dirigidas aos visitantes deste espaço de arte e registadas em vídeos, que serão transcritos, analisados e interpretados posteriormente.

Em suma, este artigo não se limita a um método ou a uma técnica: como se verá adiante, a Sociologia Artística constitui (essencialmente, se bem que não somente) uma postura epistemológica e metodológica; a nomeada Exposição Sociológica desvela-se 
mais propriamente enquanto método, que por sua vez incorpora 3 técnicas: a banda desenhada sociológica (ou sociological comics); o Inquérito visual-virtual e a galeria sociológica virtual.

Finalmente, aquilo que se entende por etapas deste processo é ainda outra coisa: como se indica logo no resumo, estas fases são, grosso modo, três: 1) a planificação do projeto na universidade ou no centro de investigação; 2) a apresentação de instrumentos da pesquisa e a interação com os visitantes na galeria de arte; 3) a posterior introdução de resultados (parciais) numa revista científica sociológica. Só assim o processo de pesquisa se pode constituir sempre em trabalho em progresso, e não instituir-se de modo definitivo. Uma tal cumplicidade aberta entre a universidade e as atividades de extensão ocorre deste modo em termos de um ciclo de hibridação que inclui pelo menos dois tipos de miscenização. Uma primeira hibridação sócio-científica ocorre entre o contexto sociológico académico e o contexto social da galeria de arte, bem como no seio da caminhada socio-científica inversa. Uma segunda hibridação racional-sensível passa-se entre o conhecimento sociológico e os saberes e sabores artísticos.

\section{A Sociologia Artística e a hibridologia}

O campo das ciências, e o continente das Ciências Sociais em particular, tem registado numerosos conflitos e ambiguidades epistemológicas e metodológicas, por exemplo quanto à delimitação dos seus territórios e pontos de contato. Afinal, existem numerosas transversalidades e interseções na rede intricada que reúne os diversos ramos e comunidades científicas das Ciências Sociais.

Por forma a contribuir, ainda que de forma incompleta, para a clarificação deste estado de coisas, introduziremos abaixo apenas os arquipélagos de conhecimento de que falamos neste artigo: a Sociologia Visual e um terreno vizinho, a Sociologia Artística.

Quanto à Sociologia Visual, inclui sobretudo objetos de estudo e métodos que se reportam seja à realidade referencial de natureza visual, seja às subjetividades, racionalidades e sensibilidades dos agentes sociais, no que respeita os processos visuais que observam ou produzem. Douglas Harper (2012), um dos pais fundadores desta área, traça os seus contornos essenciais, desde aspetos teóricos (perspetivas reflexiva e narrativa, fenomenologia, etnometodologia, semiologia) até às técnicas empíricas ativadas (etnografia visual, observação incorporada, documentário fotográfico, elicitação fotográfica e photo voice, multimédia). O livro mais recente de Luc Pauwels (2017) atualiza as posturas teóricas e metodológicas da disciplina, incluindo novos tipos de análises de imagens e de processos multimodais, uma reflexão ética e a produção e comunicação de conteúdos para o ensino, mostrando ainda variados estudos de caso. Gillian Rose (2016), uma autoridade na metodologia da Sociologia Visual, para além dos temas das primeiras edições, como a fotografia de arquivo, o documentário, os públicos e as questões de ética, publicou uma $4^{a}$ edição renovada em 2016, cobrindo novas configurações da investigação, como a análise de dados ou a pesquisa passada no ciberespaço, em sites e redes sociais digitais. 
De entre os primeiros estudos em Portugal dedicados à cultura visual urbana de um ponto de vista sociológico e não apenas em termos de crítica de arte, destacam-se as análises seguintes: interpretação do estilo e conteúdo da Arte dos Grupos Excursionistas e Jantaristas, associações que promovem um género original de cultura e turismo populares em tabernas urbanas (Andrade, 1979, 1986, 1988, 1991); reflexão sobre as obras do artista plástico Alvarez, que incluem frequentemente temáticas citadinas (Andrade, 1987). Mais tarde, um passo qualitativo foi dado através da problematização e estado da arte da Sociologia Visual, aos níveis internacional e da realidade sociológica Portuguesa, na perspetiva de uma Sociologia das Visibilidades Sociais e de uma Sociologia do Olhar (Andrade, 1995, 1997a, 1997b).

Outros estudos relevantes sobre as culturas urbanas, por vezes incidindo nas suas dimensões visuais, incluem análises acerca das festas populares na região Norte de Portugal (Pinto, Ribeiro \& Durand, 2016); ou debruçam-se sobre as transformações das culturas locais durante o processo de industrialização no Norte do País (Araújo, Cunha \& Ribeiro, 2015). Nesta perspetiva dos processos móveis na contemporaneidade, Sales (2015) discutiu o caso do acesso online. Um tal contexto digital da cidade necessita de ser revisitado em termos de criatividade dos utilizadores e cidadãos (Zagalo \& Branco, 2015).

Por seu lado, a Sociologia Artística não se confunde com a Sociologia Visual, na medida em que se ocupa das várias artes, e não apenas daquelas transmitidas visualmente. Para além disso, a Sociologia Artística também não coincide com a Sociologia da Arte. Esta última usa a arte como temática e utiliza metodologia científica, semelhante ou dissemelhante de outras áreas da sociologia. Diferentemente, a Sociologia Artística utiliza, à partida, métodos artísticos para entender as problemáticas sociais, embora os confronte, de modo assíncrono ou síncrono, com os instrumentos de recolha de informação e análise sociológica. Todavia, mesmo se aplica métodos e técnicas artísticas, a Sociologia Artística também não se confunde com a Arte Sociológica. Esta corrente artística foi proposta essencialmente por Hervé Fisher (1977), Fred Forest (1977) e Jean-Paul Thénot (2012), a partir de 1974, mesmo se o termo já existia desde 1968. A Arte Sociológica propunha desenvolver uma intervenção crítica sobre a arte e a sociedade, e ainda questionar as teorias e métodos da Sociologia. Criticava principalmente o poder e os meios de comunicação de massa, usando a participação, a provocação, o simulacro e a ironia.

Em suma, a Sociologia Artística, embora autónoma, articula-se e hibridiza-se com as Sociologias Visual e da Arte, e igualmente com a Arte Sociológica, mas na contemporaneidade que se assume, cada vez mais, como uma incomensurável rede urbana e digital, e sobretudo fundada e fundida numa natureza híbrida. Afinal, a Sociologia Artística entende-se como um saber híbrido que se pronuncia sobre as atuais realidade e sociedade híbridas. A conjunção de todos os saberes híbridos nomeia-se Hibridologia (Andrade, 2014, 2015).

Para um tal desiderato, a Sociologia Artística utiliza, entre outros instrumentos, o método da hibridação artística. Este procedimento, através da mistura de técnicas e géneros artísticos, visa a descrição, narração, interpretação, compreensão e explicação da natureza plural e profunda do social, inclusive os fenómenos culturais e artísticos. 
Para além destas tecnologias artísticas híbridas, a Sociologia Artística serve-se de teorias, conceitos, métodos e instrumentos de reflexão sociológica de natureza híbrida. Por exemplo, os conceitos híbridos, que são aqueles termos crioulos que pertencem a culturas e artes diferentes, centrais ou periféricas, globais ou locais. Mikail Bakhtin (1983), ao empreender a crítica literária de obras de proveniência cultural diversa na obra Dialogical Imagination, usa o conceito/método híbrido que ele nomeia "cronótopo", para traduzir a complexidade da articulação entre os tempos (cronos) e os espaços (topos) sociais, acionados por culturas díspares e por vezes antagónicas ou por géneros literários polissémicos. Afinal, onde acaba a cultura e a arte e começa a reflexão sobre elas?

Ora, a Hibridologia em geral, e a Sociologia Artística em particular, podem aplicar-se a múltiplos objetos de estudo sociológicos híbridos, de que daremos estes dois exemplos: a problemática das culturas móveis e a discussão sobre a comunicação turística nas redes sociais urbanas e digitais.

\section{Culturas móveis}

John Urry publicou em 1989 uma obra seminal intitulada The Tourist Gaze. Em Setembro de 2011, na $3^{\text {a }}$ edição empreendida com Jonas Larsen, o livro apresenta o título The Tourist Gaze 3.o, incorporando novas análises sobre a fotografia e o processo de digitalização [digitisation], no dizer dos autores. Este ensaio sobre o olhar do turista influenciou múltiplos trabalhos sobre as culturas móveis e as mobilidades urbanas e turísticas, conceitos também apurados por John Urry $(2007,2011)$ em diversas outras obras suas, por vezes em colaboração com Mimi Sheller (2004, 2006).

A cultura móvel constitui um paradigma emergente nas atuais sociedades móveis, onde os processos, capitais, atores e coisas, e a natureza da cultura, movem-se e transformam-se continuamente. A cultura móvel é um recente modo de fruição e conhecimento do património cultural, articulado às mobilidades e discursos sobre o urbano. Hoje, no espaço público das ruas, museus e galerias, cidadãos, turistas e diversas marginalidades sociais ativam estratégias multimodais de comunicação cultural urbana, amiúde apoiadas em média digitais como os telemóveis, tendo em vista conhecer e desfrutar o património material (monumentos, obras de arte, cinema/vídeo) e o património imaterial (música, e-património cultural). Por outras palavras, assistimos hoje à emergência de um ciberespaço e um cibertempo móveis. O cibertempo significa o conjunto de temporalidades sociais (ou cursos) acionados pelo utilizador das espacialidades sociais (percursos), no seio do ciberespaço público da internet, residente em servidores ou mobilizado por dispositivos móveis.

Retomando a distinção operada na introdução entre metodologia e métodos, existe hoje uma discussão interessante sobre as mobilidades socio-culturais e a sua interpretação sociológica. Por um lado, acerca daquelas culturas móveis subjacentes ao turismo cultural e artístico (Hanna, 2015; Kaminski, 2014). Por outro lado, no que toca as mobilidades relativas aos processos e instrumentos da investigação, especialmente quanto às pesquisas que usam dispositivos digitais móveis e que fundam, por vezes, uma cultura científica móvel. 
A epistemologia, a teoria e as metodologias inovadoras foram debatidas nos campos dessas mobilidades urbanas e digitais. De facto, Colin Hall (2005) chama a atenção para a necessidade de repensar os fundamentos epistemológicos da sociologia das mobilidades. O próprio investigador pode ser entendido como um viajante científico entre diversos contextos do social, para além dos meios académicos (Slocum, 2015). Nesta ótica, as estratégias da pesquisa em si, e a metodologia qualitativa em especial, sofreram transformações irreversíveis, como a articulação nunca dantes vista entre, de um lado, as epistemologias e as metodologias mais clássicas e, de outro lado, as chamadas ontologias, em recentes ensaios nas Ciências Sociais e Humanas. As ontologias não são mais do que conjuntos de conceitos articulados por relações específicas, constituindo uns e outras, proposições lógicas e dialéticas que delimitam uma dada área do conhecimento, em particular através de recursos e instrumentos digitais.

Em particular, a relação da viagem com a inovação tem sido considerada como central nas Ciências Sociais (Hall, 2008). O próprio estatuto epistemológico das viagens e mobilidades urbanas e digitais é posto em causa na configuração inovadora da slow travel, uma modalidade da mobilidade que pretende compreender, profundamente e através de um ritmo mais meditativo, as identidades e diferenças entre as populações e culturas mundiais, simultaneamente nos níveis global e local (Fullagar, 2012).

Outros autores e obras relevantes para este questionamento são Bruno Latour e colaboradores, que abriram o caminho para a Teoria do Ator-Rede [Actor-Network Theory]. Trata-se de uma configuração reflexiva estreitamente conectada ao seu modus operandi. Num primeiro momento, foi aplicada a terrenos empíricos académicos ou experimentais como o laboratório científico, mas procurou igualmente entender as relações sociais em contextos reticulares mais alargados, por exemplo no interior das redes sociais digitais. Esta teoria foi igualmente articulada à problemática das culturas móveis, em especial no caso do turismo (Duim, 2012). Os comportamentos de mobilidade e correspondente psicologia dos turistas encontram-se também relacionados com a respetiva sustentabilidade em políticas urbanas (Cohen, 2014). Outros métodos inovadores incluem os métodos móveis, como aqueles em que o pesquisador usa o computador portátil ou o telemóvel (Buscher, 2011), ou os métodos de investigação visuais, no caso do turismo (Rakic, 2012).

Finalmente, no que respeita o trabalho de campo empírico, nunca é demais sublinhar que nos encontramos imersos num mundo móvel, tanto como atores sociais quanto na qualidade de investigadores, como bem salienta Jennie Molz (2014). As nossas vidas quotidianas enquanto cidadãos, turistas, ou noutra condição e situação de mobilidade, constituem vidas móveis (Elliot \& Urry, 2010). Com efeito, no nosso planeta ocorrem mobilidades de natureza múltipla, como as partilhas interculturais perpetradas pelos turistas (Barker, 2014), mas igualmente as dramáticas diásporas dos imigrantes, re-localizações que requerem novas e inovadoras políticas dos lugares (Verstrate, 2009). Neste contexto de mudança acelerada, o cientista social, se quiser seguir o rasto dos outros agentes sociais de um modo rigoroso, terá igualmente que aplicar, nas suas pesquisas, as nomeadas tecnologias móveis da cidade (Scheller \& Urry, 2006). Nesta conjuntura, a própria natureza do trabalho científico de terreno metamorfoseia-se (Hall, 2011). 
Para além disso, o conceito "culturas móveis" tem raízes numa pesquisa sobre as culturas urbanas e o turismo iniciadas em 1979-80, pelo autor do presente artigo. Esta investigação foi divulgada e publicada, por um lado, através de obras sobre o turismo popular dos Grupos Excursionistas e Almoçaristas/Jantaristas (Andrade, 1981, 1986). Por outro lado, a pesquisa produziu os conceitos "inter-viagem" (hibridação entre os vários tipos de viagem: turística, profissional, política, religiosa, etc.); "turismo crítico" (postura contra o turismo de massas por parte de um turista) e "contra-turismo" (visão do mundo alternativa, por parte de autóctones das sociedades visitadas por turistas, sobre as culturas populares locais).

Estes e outros resultados foram sintetizados na proposta, por parte do autor deste artigo, de um género sociológico nomeado "Sociologia Semântico-Lógica" (Andrade, 2011a, 2011b). Um tal paradigma interpretativo do social, entre outros pedestais, é forjado no tsunami do conhecimento mobilizado pelos novos media, pelas tecnologias do ciberespaço e pelos dispositivos móveis. Com efeito, a Sociologia regista uma revolução, aos níveis epistemológico, teórico e metodológico, a partir das redes urbanas da metrópole global, articuladas às redes sociais e semânticas que subjazem à Web Social ou Web 2.o (Facebook, Twitter, Instagram, What's App) e à Web Social-Semântica ou Web 3.0 (Freebase, Google, Wikipedia). Para esse desiderato, o sociólogo pode usar o Método Geo-neo-lógico, que consiste na análise e interpretação dos processos sociais em três dimensões: os espaços (daí o prefixo "geo"'); os tempos, sobretudo os ritmos da inovação ("neo"); e o logos, conceito que significa a linguagem da razão, ou a razão da linguagem, ouvida, conversada ou escrita pelos sujeitos sociais. Uma tal tricotomia é inspirada no conceito deixis da Filosofia grega, mas aplicado ao social.

Recentemente, esta análise foi aperfeiçoada num ensaio sobre o "e-turismo cultural", ou seja o turismo ocorrido nas redes urbanas, culturais e digitais. Cidadãos, turistas e imigrantes representam e apresentam as suas próprias viagens de trabalho, de lazer e de saber, através do discurso produzido e reproduzido por meio das suas próprias deslocações, mobilidades e respetivas descrições, narrações e opiniões, no tecido da cidade e nas redes do "e-património cultural" (Andrade, 2017).

Hoje em dia, os telemóveis ativam aplicativos incluindo realidade aumentada para perfis de consumidores como jovens, turistas e marginalidades sociais: i.e. apresentam localidades reais em imagens, vídeo ou 3D, e informação em tempo real sobre elas. Esta tendência inaugura uma cultura urbana e turismo aumentados, onde a realidade dos tempos livres aos horários laborais, é reforçada pela articulação entre entretenimento espetacular, informações pertinentes sobre lugares visitados e eventos culturais. As cidades de Braga (em Portugal) e do Noroeste têm acompanhado tais estratégias de desenvolvimento inteligente para a cultura móvel, como Braga Cidade Criativa Unesco e Smart City. Para além disso, no quadro das sociedades de risco coesas, um termo sugerido por Ulrick Beck (1992), importa refletir sobre riscos como o fetichismo da cultura urbana digital e a reificação do mercado turístico; ou as suas potencialidades, por exemplo uma troca inter/transcultural mais intensa na urbe e um melhor conhecimento das sociedades visitadas pelos turistas. 


\section{UMA ESTRATÉGIA PARA O ESTUdO DA COMUNICAÇÃO URBANA E TURÍSTICA MÓVEIS}

As visibilidades ou invisibilidades urbanas constituem processos comunicativos que ocorrem ao nível contextual da cidade mediadora. Esta intermediação articula dois níveis do social: por um lado, as visões do mundo circulantes na urbe, de acordo com as estruturas sociais incorporadas nos agentes urbanos, como a idade, género, classe social, etnia, grau de formação, etc.; e, por outro lado, as visualidades sociais microscópicas inerentes à vida quotidiana (Andrade, 1995, 1997a, 1997b).

Uma tal problemática do (in)visível urbano adquire especial relevo no quadro das mobilidades urbanas, e em particular no seio da comunicação urbana e turística móveis. Por exemplo, no caso das deslocações de turistas culturais a determinados locais da urbe, como os museus e as galerias de arte, aos quais subjazem modos de comunicação específicos. O projeto "Cultura Móvel e Comunicação Turística" visa precisamente aprofundar um tal processo, desde fevereiro de 2017 '.

As (in)visibilidades metropolitanas partilhadas pelo projeto Cultura Móvel e pela publicitação de algumas das suas atividades na Exposição NewArtFest'17, abaixo desenvolvidas, sejam elas de natureza cidadã, turísticas ou migrante, baseiam-se numa intervenção, não apenas teórica mas também prática e participativa, no tecido urbano. Uma tal ação coletiva é entendida enquanto Sociologia Artística e artes digitais-virtuais de vanguarda, mas também funcionando como veículo de partilha de experiências culturais no seio do atual mundo intercultural e transcultural.

\section{Sociologia Artística e o monumento híbrido}

Um monumento híbrido desvela-se como um edifício que opera a fusão de vários monumentos, a fim de celebrar um património cultural simultaneamente autónomo e comum. Pode ajudar cidadãos, turistas e migrantes a compreender o património cultural local ou mundial, dentro de uma estratégia transcultural. Transcultural significa a transformação da cultura em conhecimento, em particular nos contextos da Cidade 3.0 e do Turismo 3.0, ideias definidas na seção seguinte deste texto.

A torre de Belém em Lisboa e a Torre Eiffel em Paris revelam-se como dois notáveis ícones urbanos culturais e turísticos. Através de sua hibridação, eles constituem um exemplo aliciante de monumento híbrido (Figura 1).

Com efeito, não constituem exatamente torres gémeas, mas testemunham um processo comum de herança cultural. A Torre de Belém é uma metáfora de navio, para celebrar as descobertas portuguesas no século XVI, que iniciaram o processo de globalização, de acordo com Immanuel Wallerstein (2011). A Torre Eiffel significa um símbolo de outra globalização, a revolução industrial ao redor do mundo no século XIX. No entanto, a hibridização destas duas torres, tão díspares mas tão semelhantes, informa-nos que devemos diferenciar e conectar todas as culturas do mundo, de forma dialógica, democrática e igualitária.

'O projeto "Cultura Móvel e Comunicação Turística" reúne uma equipa coordenada pelo autor deste artigo, e constituída no Centro de Estudos e Sociedade da Universidade do Minho, em Braga, Portugal. 


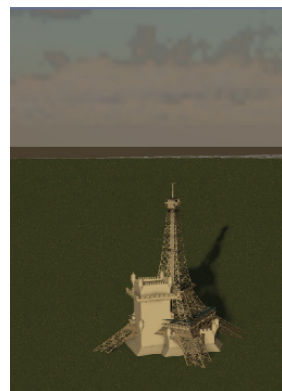

Figura 1: Monumento híbrido

Afinal, a Hibridologia também se define como o estudo das entidades num mundo intercultural e transcultural. Aliás, a Hibridologia usa hibrimédia, isto é um medium que transforma os média originários (iniciais num dado processo), como o medium edifício (exemplificados aqui na Torre de Belém e na Torre Eiffel), em média originais ou inovadores (o medium edifício híbrido, aqui ilustrado através do monumento híbrido).

\section{Turismo 3.0 e Cidade 3.0}

Diversas posturas teóricas opinam sobre aquilo que constitui os fenómenos do Turismo 3.0 aliados ao contexto da Cidade 3.0.

Greg Richards (2011) define o Turismo 3.0 a partir destes atributos: maior interesse dos turistas pelo património intangível; superação da dicotomia entre alta cultura e cultura popular, por exemplo testemunhado pela abertura do turista à parte de rua; hibridação entre produção e consumo cultural; desejo de experiências autênticas na viagem turística. Este autor relaciona o Turismo $3.0 \mathrm{com}$ a nomeada Cultura 3.0 (Sacco, 2011), com a qual partilha características. Para além do entendimento da cultura como um produto derivado da economia industrial nos séculos XVIII e XX (Cultura 1.0), ou da conceção da cultura como indústria cultural no século XX (Cultura 2.0), a noção de Cultura 3.0, associada às novas tecnologias digitais, significa que a cultura constitui um meio de criar identidade e valores, estimular a coesão social e incentivar a criatividade. O próprio John Urry, como foi já referido acima, atualizou em 2011 o título da edição de 2009 do clássico The Tourist Gaze para The Tourist Gaze 3.0.

No entanto, a meu ver, estas posturas, para a definição do Turismo 3.0 e Cidade 3.0, não consideram suficientemente diversos fenómenos complexos inerentes às redes sociais urbanas, bem como aqueles que subjazem às redes sociais digitais características da Web 2.0 e da Web 3.0 (Andrade, 2011b), noções que esclareceremos a seguir.

Em primeiro lugar, o turista, ao visitar uma localidade, recolhe não apenas informações relativas ao lugar visitado, mas igualmente saberes e sabores caraterísticos desses lugares urbanos (Andrade, 1992). De facto, qualquer localidade funda-se e funde-se em redes sociais locais, no interior dos seus espaço e tempo físicos e geográficos. Um exemplo é a taberna portuguesa. Neste espaço-tempo, desfrutam-se sabores locais (comidas, bebidas, etc.), mas também saberes locais (costumes, valores, tradições, inovações, etc.). Estas redes sociais urbanas incluem pessoas, objetos, espaços e tempos quotidianos e coletivos. 
Em segundo lugar, o turismo de massas apoia-se hoje em redes sociais digitais, que constituem um novo paradigma relativamente a essas redes sociais pré-modernas e locativas, que se transformaram recentemente em redes sociais globais.

Tais redes sociais digitais organizam-se não apenas no ciberespaço, mas também no cibertempo. Recorde-se que este conceito significa o conjunto de passos percorridos nas redes do espaço público virtual, e ocorridos através de determinados compassos no tempo público digital.

Nos anos 90 do século passado, os utilizadores da internet podiam ler informação mas quase não escreviam, sendo assim a sua participação algo limitada. Este modelo de comunicação chama-se Web 1.o.

Desde a primeira década do terceiro milénio, os passantes e passeantes na internet, leem e escrevem informação de um modo mais corrente e profundo, em atividades deste modo mais participativas. Entrou-se assim na nomeada Web 2.0 ou Web social (Facebook, Twitter, Instagram, etc.), no seio da qual cidadãos e turistas utilizam extensiva e intensivamente, desde há alguns anos, dispositivos móveis.

Na segunda década do século XXI, emerge a Web 3.0 ou Web social-semântica. Isto é, nos sites, blogues, wikis e redes da Web 3.0, para além da informação, partilham-se, de um modo mais profundo do que sucede na Web 2.o, opiniões e interpretações sobre o sentido da informação circulante. Ou seja, para além de rede social, a Web 3.o revela-se como uma rede semântica, na medida em que faculta significados sobre as ações e palavras ditas pelos seus utilizadores em conexão reticular. Alguns exemplos pioneiros são a Wikipédia ou os wikis em geral e o projeto "Freebase", recentemente adquirido pela Google.

Num primeiro momento, seja o habitante seja o turista, ou mesmo o imigrante e outras marginalidades sociais, descobrem que a sociedade é uma SO(C)IDADE, ou seja, uma cidade social. Esta cidade social significa que o espaço urbano pode ser desfrutado através da arte e da reflexão sobre o quotidiano dos seus habitantes e visitantes. Uma tal fruição do espaço e tempo de lazer urbanos pelos cidadãos locais e globais, hoje em dia, é realizada frequentemente através de dispositivos móveis, como o telemóvel.

Estes dispositivos móveis constituem verdadeiros computadores de bolso, que mostram não apenas informação. Num segundo momento, permitem igualmente a partilha de incomensuráveis conhecimentos sobre as sociedades e culturas visitadas, bem como acerca dos seus visitantes.

Por outras palavras, a urbe torna-se uma Cidade 3.0 ou cidade social-semântica, ou seja, aquela localidade globalizada cujo derradeiro significado atual é o seguinte: uma rede urbana geográfica que usa redes digitais, sociais mas também semânticas, caraterísticas da Web 3.0, em particular nas atividades do Turismo 3.0.

\section{A Sociologia Artística: uma configuração epistemologia e metodológica INOVADORA?}

Em seguida, procuraremos aplicar as considerações anteriores a atividades de extensão incluídas no projeto "Cultura Móvel e Comunicação Turística”, acima referido, 
utilizando diversas posturas sociológicas, tecnologias digitais e estratégias artísticas. Os conteúdos sociológicos abaixo reportados, e incluídos nos anexos 1 a 4, foram expostos no evento de arte digital NewArtFest'17, na forma híbrida da metodologia circunscrita atrás como Sociologia Artística, na secção "A Sociologia Artística e a Hibridologia". Recorde-se que uma metodologia pode ser entendida, em parte, como uma grelha de problematização ou uma gramática de métodos e técnicas. Como veremos adiante, esta metodologia circunscreve o método nomeado Exposição Sociológica, que por sua vez inclui três técnicas: a banda desenhada sociológica (ou sociological comics); o inquérito visual-virtual e a galeria sociológica virtual.

Tais propostas são mostradas brevemente nos anexos 2, 3 e 4, e em duas formas pedagógicas simples, dirigidas a estudantes, professores e investigadores, entre outros públicos da pesquisa Por um lado, as fichas de obra de arte, para além de terem sido usadas na organização do evento NewArtFest'17, permitem definir conteúdos sociais e sociológicos de uma forma sucinta, e mostrar empiricamente como se elabora uma ficha técnica para efeitos de gestão ou animação de exposições, em atividades de extensão num museu, galeria de arte, ou em outros espaços públicos urbanos. Por outro lado, as ilustrações fornecem uma perspetiva mais icónica das racionalidades e sensibilidades envolvidas tanto na experiência das culturas urbanas e turísticas pelo cidadão, quanto na sua interpretação e explicação pelo sociólogo.

No que toca ao campo empírico e ao trabalho de terreno no quadro da Sociologia Artística, talvez seja aqui que alguma inovação possa ser creditada ao presente ensaio. Por um lado, são usadas técnicas originais como a banda desenhada sociológica [sociological comics], e novas tecnologias como a realidade aumentada na técnica Galeria Sociológica Visual-Virtual. Trata-se de tentativas para desdobrar a escrita sociológica em novos media e recursos argumentativos, mais ativos e sedutores para a expressão e desenvolvimento das literacias científica, tecnológica a artística, por parte do investigador e do professor.

Por outro lado, busca-se sensibilizar cidadãos, turistas e marginalidades urbanas para a necessidade de usar a Sociologia como um meio e um média para entenderem a sua vida quotidiana, e assim transformarem-se em públicos da investigação. Neste aspeto, torna-se central estender e entender as práticas e opiniões dessas audiências, relativamente à apresentação e exposição de material sociológico em territórios pouco usuais, como o museu ou a galeria de arte, ou noutros lugares da esfera pública, por exemplo a rua e as suas paredes, que funcionarão também como palimpsestos do saber académico, mas em diálogo estreito e escorreito com o conhecimento ordinário. Talvez assim se possa contribuir para problematizar as questões sociais e sociológicas de um modo mais aliciante e participativo, testar hipóteses de maneira mais alargada e convincente e disseminar o trabalho em curso da investigação a um público mais alargado, que não se confine aos portões da academia.

\section{O MÉTOdo DA EXPosição SociológICA}

$\mathrm{Na}$ exposição sociológica, diversos perfis de públicos, filmados pelo sociólogo, comentaram, discutiram, apreciaram ou criticaram conteúdos, objetos de estudo e 
métodos sociológicos, mostrados num território externo à universidade, a exposição de artes visuais, como se de objetos artísticos se tratassem. Este dispositivo, simultaneamente discursivo e contra-discursivo, coloca em questão não apenas alguns métodos pedagógicos tradicionais, por exemplo a mera apresentação em powerpoint na sala de aula, como a metodologia da pesquisa e ainda a própria exposição de arte. Tais processos dever-se-iam hibridizar mais profundamente, nestes territórios pedagógicos e de investigação plurais, como em outros espaços e tempos alternativos

\section{A TÉCNICA BANDA DESENHADA SOCIOLÓGICA}

Esta técnica tenta articular, por meio de uma história: (a) o conhecimento implementado por instituições localizadas na cidade contemporânea comunicativa, democrática e digital, como a academia; (b) por outro lado, o conhecimento produzido pelos cidadãos digitais urbanos. E faz isso através de uma maneira particular de apresentação de conteúdos ou conhecimento, ou seja, uma banda desenhada. No entanto, as questões sociais não são apenas entendidas e usadas como um tema substantivo para impulsionar esta "história sociológica". Elas também estão imersas no próprio modo de representar e apresentar mundos reais ou imaginários. Por exemplo, os problemas sociais podem não ser apenas narrados, mas também analisados por meio de uma pesquisa sociológica que usa argumentos visuais e textuais dentro dos quadros da banda desenhada (consultar a Ficha Técnica 1 e as figuras 4 a 10).

\section{A TÉCNICA INQUÉRITO VISUAL-VIRTUAI}

A segunda técnica de Sociologia Artística pretende superar algumas desvantagens do inquérito sociológico, como a forma algo rotineira e pouco motivadora do questionário tradicional, nas suas formas da administração direta ou indireta. Para tal, foi elaborado um inquérito visual-virtual em vídeo com animação em $2 \mathrm{D}$, que incluiu uma questão central sobre a atualidade económica, política e cultural das nossas sociedades em rede, globais/locais e transculturais (consultar a Ficha Técnica 2 e as Figuras 12 a 19)

\section{A técnica Galeria Sociológica Virtual}

Finalmente, a terceira técnica aplica tecnologias digitais recentes à investigação sociológica. Edmund Husserl (1975) circunscreve o processo fenomenológico em três fases centrais: perceção, consciência e conhecimento do real. Quanto ao conhecimento, no quadro de uma genealogia da lógica, analisa a experiência pré-predicativa, a estrutura do pensamento predicativo e a origem do pensamento concetual. Alfred Schultz (1967) adapta a fenomenologia de Husserl à realidade social, estabelecendo os fundamentos e pedestais da ação do cidadão participativo nos mundos da vida quotidiana [lebenwelt].

No caso da Galeria Sociológica Virtual, a Realidade Híbrida consiste num modo de experiência, consciência e conhecimento da realidade cultural urbana, de uma forma 
inédita. De facto, a Galeria Sociológica Virtual hibridiza a realidade real dos públicos visitantes da exposição, aos seus modos interpretativos e lógicos mobilizados pelo cientista social, por exemplo a Realidade Virtual (imersão em mundos virtuais em 3D) e a Realidade Aumentada (experiência de um mundo virtual em 3D acrescido, em tempo real, de informações textuais, estatísticas, geográficas ou outras). As consequências epistemológicas e metodológicas, para o ensino e para a investigação sociológicas inovadores, adivinham-se decisivas.

Por exemplo, é possível animar uma aula sobre património cultural e turismo, a partir da apresentação de fontes e debates usando dispositivos móveis e aplicações de Realidade Aumentada. Ou usar este hardware e software na recolha, análise, interpretação e disseminação de conteúdos em projetos de pesquisa, não apenas na academia, mas igualmente nos lugares urbanos de cultura onde o cidadão e o turista partilham os seus itinerários quotidianos, no seio de um diálogo intercultural e híbrido (ver Anexo 4, Ficha técnica 3 e figuras 20 a 23 ).

\section{ConclusÃo}

Em termos de balanço final, retomemos algumas das questões colocadas, no sentido de propor pistas para um debate e combate urgentes.

Quanto aos resultados, sempre provisórios em matérias móveis como a que nos propusemos abordar, e no que respeita ao desassossego epistemológico anunciado e enunciado logo na Introdução, parece-nos que a Hibridologia (ou seja, o estudo das entidades híbridas por parte de saberes híbridos), circunscrever-se-á, nos anos vindouros, como uma das arenas de discussão mais prementes. Por exemplo, algumas das problemáticas no campo do interculturalismo e transculturalismo, como o discurso dos média sobre os agentes sociais percebidos como "híbridos", sejam eles retornados, imigrantes ou refugiados (Marinho, 2015). Ao nível da reflexão teórica no campo sociológico, os conceitos "cultura móvel" e "comunicação urbana e turística" afirmar-se-ão provavelmente como duas pedras basilares das Sociologias da Comunicação e dos Novos Media. No plano das metodologias, a Sociologia Artística, acima delineada, estabelecerá uma das mestiçagens possíveis e prováveis entre o conhecimento racional e as sabedorias sensíveis.

No que respeita aos escolhos e limitações da investigação, esta caminhada e viagem do conhecimento comporta, certamente, incertezas. Contudo, o risco da escrita sociológica nunca se opera sem riscos sociais, profissionais, epistemológicos e sociológicos.

Sobre os futuros aperfeiçoamentos exequíveis, uma tal estratégia só será possível através do diálogo e partilha de, pelo menos, três modos de conhecimento: o conhecimento científico, os saberes profissionais de instituições mediadoras como o museu, e os saberes comuns ou ordinários do novo público da investigação que emerge, paulatinamente, nas redes sociais urbanas e digitais, e que inclui os seguintes agentes sociais: desde logo o cidadão e o turista, mas ainda as diversas marginalidades sociais, entre outras: os reformados, os deficientes, os imigrantes, as minoras étnicas, de género, políticas e religiosas. 
Finalmente, no que toca os passos futuros, cabe a todos nós, escritores e leitores das Ciências Sociais e Humanas, públicos do conhecimento e audiências da investigação, participar neste e noutros debates coletivos necessários, onde as dificuldades e os sucessos, as inovações e as repetições, entrelaçam-se em redes sociais, científicas, tecnológicas e artísticas solidárias nunca dantes vistas, que visem a produção, a interpretação e a disseminação de saberes crioulos e sem certezas definitivas. Afinal, todos nós somos, em maior ou menor escala, cidadãos, turistas e imigrantes dos conhecimentos científico, tecnológico e artístico que se querem críticos, mas, do mesmo modo, e por pouco que seja, inovadores.

\section{REFERÊNCIAS BIBLIOGRÁFICAS}

Andrade, P. (1979). A taberna. Arte-Opinião, 6, 13-16.

Andrade, P. (1981). Les groupes 'excursionistes'-'de déjeuners' portugais et leur art. Paris: École des Hautes Études en Sciences Sociales.

Andrade, P. (1986). A arte excursionista. Colóquio-Artes, 68, 5-11.

Andrade, P. (1987). Alvarez, pintor dionisíaco. Colóquio-Artes, 74, 20-25.

Andrade, P. (1988). O beber e a tasca: práticas tabernais em corpo vínico. Povos e Culturas, 2, 223-263.

Andrade, P. (1991). A taberna mediática, local reticular de negociações sociais e sociológicas. Revista Crítica de Ciências Sociais, 33, 265-286.

Andrade, P. (1992, 5 de fevereiro). A taberna e o beber, seus sabores e saberes. Correio das Regiões, p. 6.

Andrade, P. (1995a). Editorial português. Atalaia, 1/2, 15-21.

Andrade, P. (1995b). A negociação do visível: as visibilidades sociais enquanto objecto teórico ilustrativo da Sociologia interdimensional e mediadora-I, Atalaia, 1/2, 73-93.

Andrade, P. (1997a). A negociação do visível-II: o tempo das visibilidades sociais e as visões da natureza. Atalaia, 3, 143-151.

Andrade, P. (1997b). Sociologia do olhar: um novo olhar sobre a sociologia? Atalaia, 3, 197-201.

Andrade, P. (2011a). Sociologia semântico-lógica da web 2.0/3.0 na sociedade da investigação: significados e discursos quotidianos em blogs, wikis, mundos/museus virtuais e redes sociais semântico-lógicas. Lisboa: Edições Caleidoscópio.

Andrade, P. (2011b, fevereiro).Tourism imaginaries and web 3.0: a quest of meaning at the art museum. Comunicação apresentada no congresso International Conference Tourism Imaginaries, Berkeley, University of California.

Andrade, P. (2014). Post-colonial co-ordinary literature and web 2.0/3.0: thinking back within transmediatic knowledge. In M. Pope(Ed.), New literary hybrids in the age of multimedia expression: crossing borders, crossing genres (pp. 123-144). Amsterdão/Filadélfia: John Benjamins Publishing.

Andrade, P. (2015). Hybridologie. In M. Veyrat, (Ed.), 110 notions sur les arts numériques (pp. 179-80). Paris: Les Éditions de l'Immatériel. 
Andrade, P. (2017). Cultural e-tourism depicted by digital discourse: innovative mobilities at urban e-heritage networks. In M. Bielenia-Grajewska \& M. Ríos (Eds), Innovative perspectives on tourism discourse (pp. 1-17). Hershey: IGI Global.

Bakhtin, M. (1983). The dialogic imagination: four essays. Austin: University of Texas Press.

Barker, A. (2014). Identity and intercultural exchange in travel and tourism. Bristol: Channel View Publications.

Beck, U. (1992). Risk society: towards a new modernity. Londres: Sage.

Büscher, M. \& Urry, J. (2011). Mobile methods. Londres Routledge.

Cohen, S. \& Higham, J. (Eds.) (2014) Understanding and governing sustainable tourism mobility: psychological and behavioural approaches. Londres: Routledge.

Dillman, D., Smyth, J. \& Christina, L. (2009). Internet, mail and mixed-mode surveys: thetailored design method. Hoboken: John Wiley \& Sons.

Duim, R., Ren, C. \& Johannesson, G. (Eds.) (2012). Actor-network theory and tourism: ordering, materiality and multiplicity. Londres: Routledge.

Elliott, A. \& Urry, J. (2010). Mobile lives. Londres: Routledge.

Fischer, H. (1977). Theorie de l'art sociologique. Paris: Casterman.

Flanagan, M. (2009). Critical play: radical game design. Cambridge, Massachussets: The MIT Press.

Forest, F. (1977). Art sociologique vidéo: dossier Fred Forest. Paris: UGE.

Fullagar, S., Markwell, K. \& Wilson, E. (Eds.) (2012). Slow travel and tourism: experiences and mobilities. Bristol: Channel View Publications.

Gleick, J. (2008). Chaos: making a new science. Londres: Penguin Books.

Goodson, L. (Ed.) (2004). Qualitative research in tourism: ontologies, epistemologies and methodologies. Londres: Routledge.

Hall, C. (2005). Tourism: rethinking the social science of mobility. Upper Saddle River: Pearson/Prentice Hall.

Hall, C. (2011). Fieldwork in tourism: methods, issues and reflections. Londres: Routledge.

Hall, C. \& Williams, A. (2008). Tourism and innovation. Londres: Routledge.

Hanna, S., Potter, A., Modlin, E., Carter, P. \& Butler, L. (Eds.) (2015). Social memory and heritage tourism methodologies. Londres: Routledge.

Harper, D. (2012). Visual sociology. Londres: Routledge.

Husserl, E. (1975). Experience and judgment. Illinois: Northwestern University Press.

Kaminski, J., Benson, A. \& Arnold, D. (Eds) (2014). Contemporary issues in cultural heritage tourism. Londres: Routledge.

Kozinets, R. (2012). Netnography: doing ethnography research online. Londres: Sage.

Leavy, P. (2009). Method meets art: arts-based research practice. Nova lorque: The Guilford Press. 
Marinho, S. (2015). Retornados e refugiados: as histórias dos media. In M. Pinto; S. Pereira \& M. J. Brites (Eds.), Os media e a crise dos refugiados: agenda de atividades (p. 9). Braga: CECS, Universidade do Minho.

Molz, J. (2014). Travel connections: tourism, technology and togetherness in a mobile world. Londres: Routledge.

Paquette, G. (2010). Visual knowledge modelling for semantic web technologies: models and ontologies. Nova lorque: Hershey.

Pauwels, L. (2006). Representing moving cultures: expression, mutivocality, and reflexivity in anthropological and sociological filmaking. In Luc Pawels (Ed.), Visual cultures of science: rethinking representation practices in knowledge building and science communication (pp. 120-152). Hanover: University Press of New England.

Pauwels, L. (2017). Reframing visual social science: towards a more visual sociology and anthropology. Cambridge: Cambridge University Press.

Pinto, M., Ribeiro, R. \& Durand, J. (2017). Bugiada e mouriscada de Sobrado: a festa como património. In M. Menezes, J. Costa \& J. Rodrigues(Eds.), Intangibility matters. Proceedings IMaTTe 2017 International conference on the values of tangible heritage (pp. 83-84). Lisboa, 29-30 de maio de 2017. LNEC: Lisboa.

Rakic, T. \& Chambers, D. (2012). An introduction to visual research methods in tourism. Londres: Routledge.

Richards, G. (2011). Creativity and tourism: the state of the art. Annals of Tourism Research, 38(4), 1225-1253.

Rose, G. (2016). Visual methodologies: an introduction to researching with visual materials. Londres: Sage.

Sacco, P. (2011). Culture 3.0: A new perspective for the UE 2014-2020 structural funds programming. [Paper for the OCM Working Group on Cultural and Creative Industries, April 2011].

Sales, C. (2015). In the meantime or the (ab)use of online accessing during mobility. Comunicação e Sociedade, 28, 229-251.

Schutz, A. (1967). Phenomenology of the social world. Illinois: Northwestern University Press.

Sheller, M. \& Urry, J. (2004). Tourism mobilities : places to play, places in play. Londres: Routledge.

Sheller, M. \& Urry, J. (2006). Mobile technologies in the city. Londres: Routledge.

Slocum, S. \& Kline, C. (Eds.) (2015). Scientific tourism: researchers as travellers. Londres: Routledge.

Thenot, J. (2012). Petit traité d'existence à l'usage des jeunes artistes et des amateurs d'art. Grenoble: Critères Editions.

Urry, J. (2007). Mobilities. Cambridge: Polity Press.

Urry, J. \& Larsen, J. (2011). The Tourist gaze 3.0. Londres: Sage.

Verstraete, G. (2009). Tracking Europe: mobility, diaspora, and the politics of location. Durham: Duke University Press.

Wallerstein, I. (2011). The modern world-system I: capitalist agriculture and the origins of the European world economy in the sixteenth century. Califórnia: University of California Press.

Zagalo, N. \& Branco, P. (2015). Creativity in the digital age. Londres: Springer. 


\section{NOTA BIOGRÁFICA}

Pedro Andrade é investigador na Universidade do Minho e doutorado em Sociologia da Cultura pela FCSH-Universidade Nova Lisboa. Ensinou de Sociologia nas Universidades de Coimbra, Lisboa e Minho. Áreas: Sociologia, Artes Visuais/Cinema, Comunicação/Redes Sociais, Metodologias e Hipermédia. Coordenador de projectos financiados pela FCT: "Literacia Científico-Tecnológica e Opinião Pública: o caso dos Museus de Ciência"; "Comunicação Pública das Artes: o caso dos Museus de Arte Locais/ Globais". Enquanto membro da Paris Film Coop, realizou: Film Saboté Spatial e Cinéma Corps. Obras em hipermédia/hibrimédia: $1^{\mathrm{a}}$ web page cultural Portuguesa (1995). Jogos Sociológicos (2006). Blog Híbrido (2006). Novela GeoNeoLógica (2009). Sites Sociais-Semânticos nas redes das Web 2.0 e Web 3.0 (2011). Sociological Comics (2013/2016).

E-mail:pjoandrade@gmail.com

Morada: Calçada dos Mestres, 7, 4 B, 1070-176 Lisboa

Centro de Estudos de Comunicação e Sociedade. Campus de Gualtar. 4710-057

Braga, Portugal

\section{* Submetido: 30.11 .2017 \\ * Aceite: 15.03.2018}

\section{Anexo 1: A exposiçÃo New Art Fest'17, enQuANTo terReno empírico PARA A APRESENTAÇÃo DE METODOLOGIAS SOCIOLÓGICAS DESENVOLVIDAS NO PROJETO "CULTURA

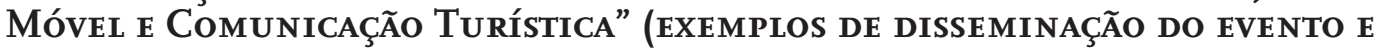 OBSERVAÇÃO DIRETA DA INAUGURAÇÃO DA EXPOSIÇÃo)}

Em outubro e novembro de 2017 , em Lisboa, foram co-organizadas as primeiras ações do projeto "Cultura Móvel e Comunicação Turística", para além do anterior trabalho de planificação realizado em Braga. O intuito foi duplo: por um lado, comunicar aos cidadãos Portugueses e aos viajantes na cidade de Lisboa (turistas, imigrantes, etc.) uma pré-visão da cidade, ou seja, visualizá-la antes de eles olharem para a pluralidade da vida quotidiana lisboeta e de outros eventos culturais); mas também disseminar uma pós-visão, isto é, um olhar visual depois do visionamento presencial da cidade.

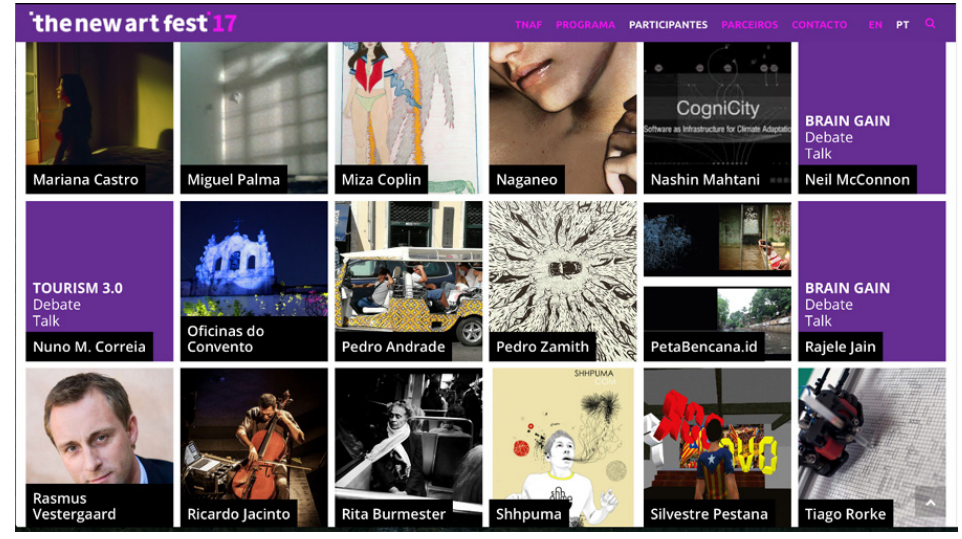

Figura 2: Programa e autores participantes no evento cultural NewArtFest'17 (extrato) 
O projeto "Cultura Móvel" permutou várias temáticas seminais com o evento, que gira à volta dos mais recentes fenómenos de turismo e de cidade.

Lê-se logo no manifesto do site que os dois principais 'sabores' do evento são a cidade social-semântica (fundada nas redes sociais e semânticas, urbanas e digitais) e a 'cidade GeoNeoLógica', ou seja, a urbe móvel no espaço, tempo e logos, tricotomia que, como apontado supra, baseia-se na deixis grega.
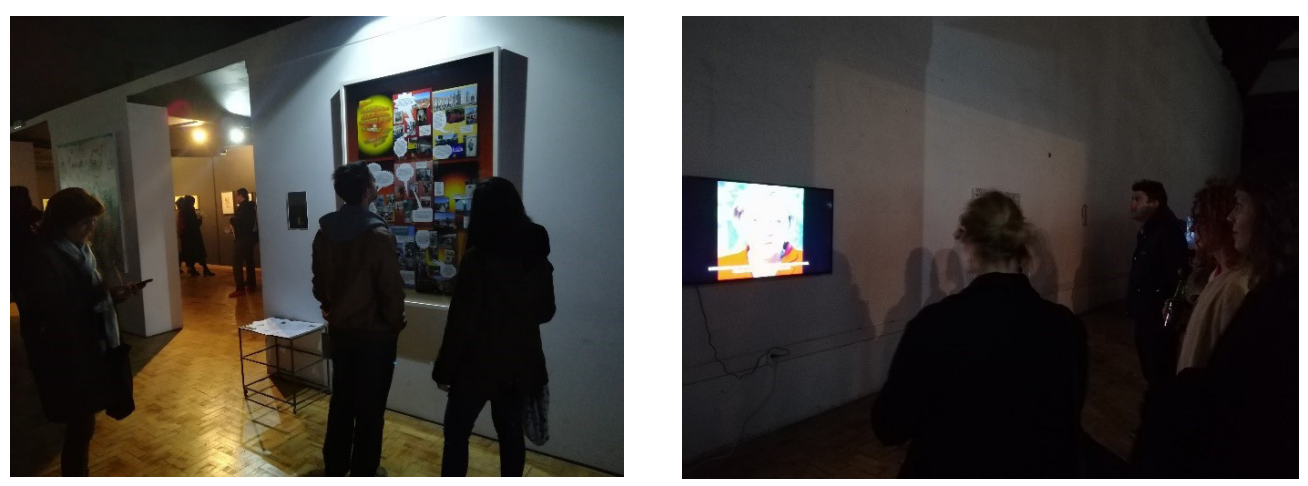

Figura 3: Audiência visionando as obras Exposição Sociológica e Galeria Sociológica Virtual (à esquerda) e Inquérito Virtual (à direita)

\section{Anexo 2: O mÉtodo da Exposição Sociológica Aplicado ao Turismo 3.0 / Cidade 3.0} E A TÉCNICA BANDA DESENHADA SOCIOLÓGICA

\section{Ficha técnica 1:}

Título(s) da obra: Exposição Sociológica sobre Turismo 3.0 / Cidade 3.o: Arte Móvel, de Artistas para Turistas e Cidadãos

Ano: 2017

Técnica/Medium: Banda Desenhada Sociológica, a partir de montagem de fotografias.

Formato: $2 \mathrm{D}$

Dimensão: 1,5x1m.

Sinopse: esta obra de arte entende-se como uma exposição sociológica acerca do Turismo 3.0 na Cidade 3.o. Em particular, esclarece o significado da arte móvel, no contexto das redes sociais e semânticas contemporâneas, acionadas por cidadãos e turistas. Uma tal proposta de arte constitui um paratexto, no dizer de Gerard Genette. Ou seja, trata-se de um conjunto de conteúdos que funciona como um cartão de visita ou um aperitivo, para apresentação de outros conteúdos, como aqueles que se incluem em outras obras de arte do mesmo artista, por exemplo o Inquérito Virtual e a Galeria Sociológica Virtual sobre a Cidade 3.0 / Turismo 3.0.

Equipamento necessário para sua montagem e/ou exibição: montagem pela empresa $\mathrm{X}$; Necessidades específicas para montagem, transporte ou outros: transporte pela empresa $X$ 


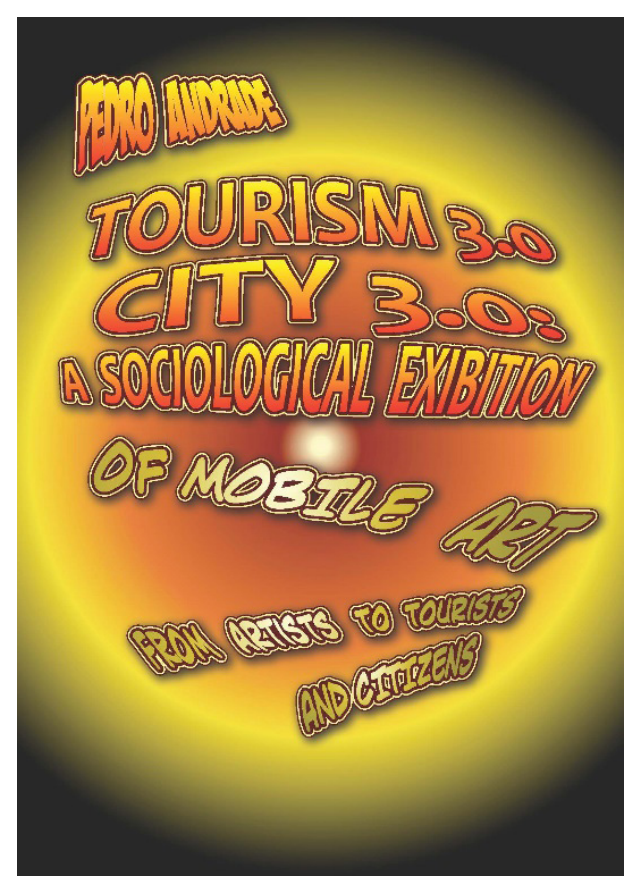

Figura 4: Exposição Sociológica

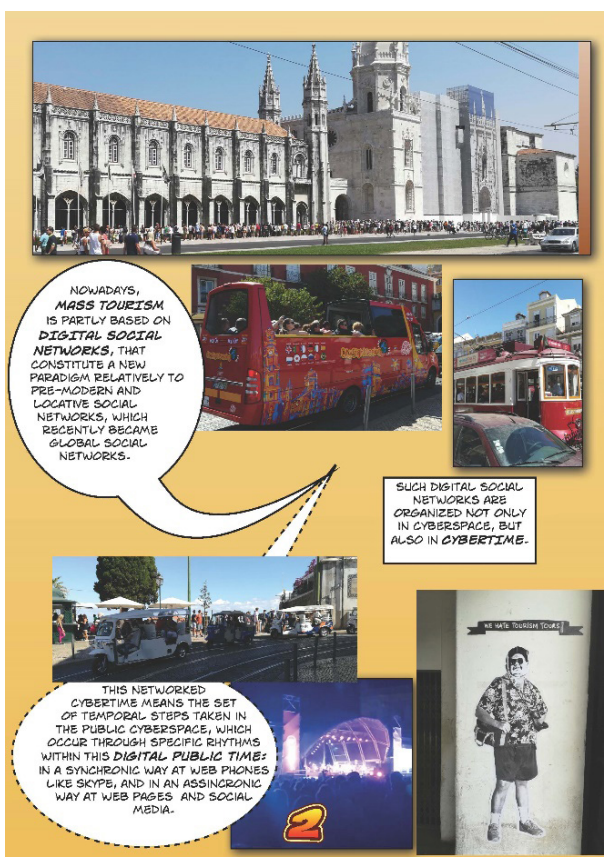

Figura 6: Turismo de massas

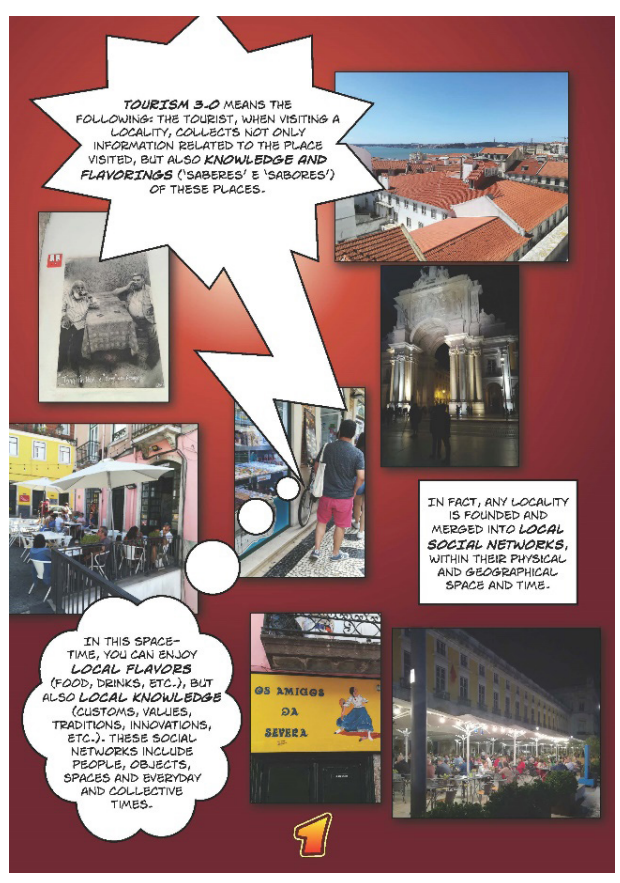

Figura 5: Turismo 3.0

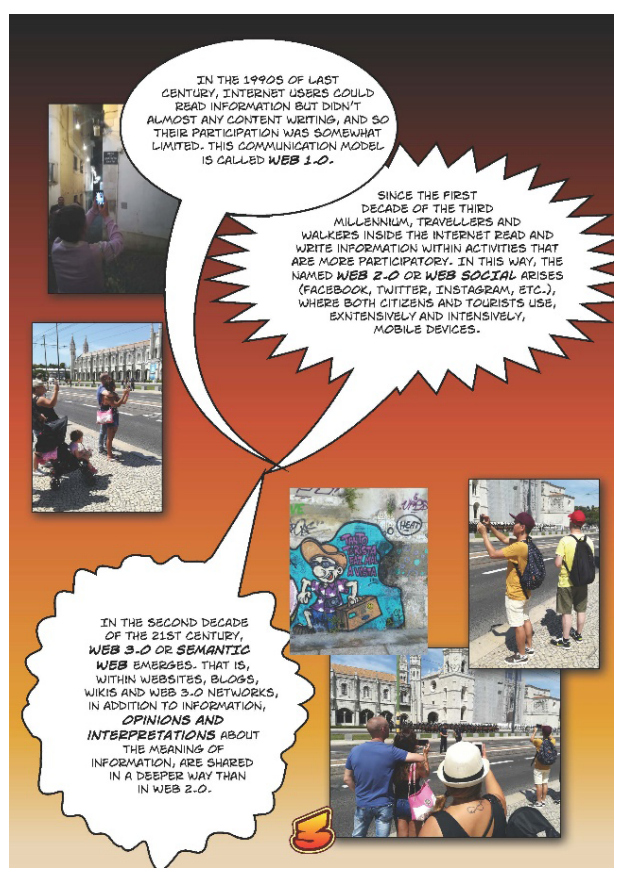

Figura 7: As 3 idades da internet: Web 1.0, Web 2.0 e Web 3.0 


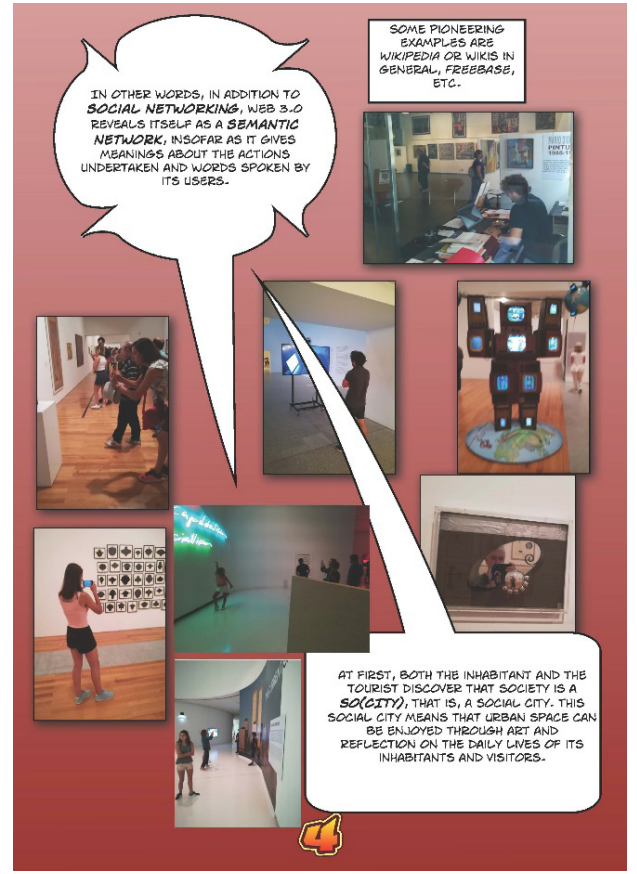

Figura 8: A Sociedade é uma So(City)

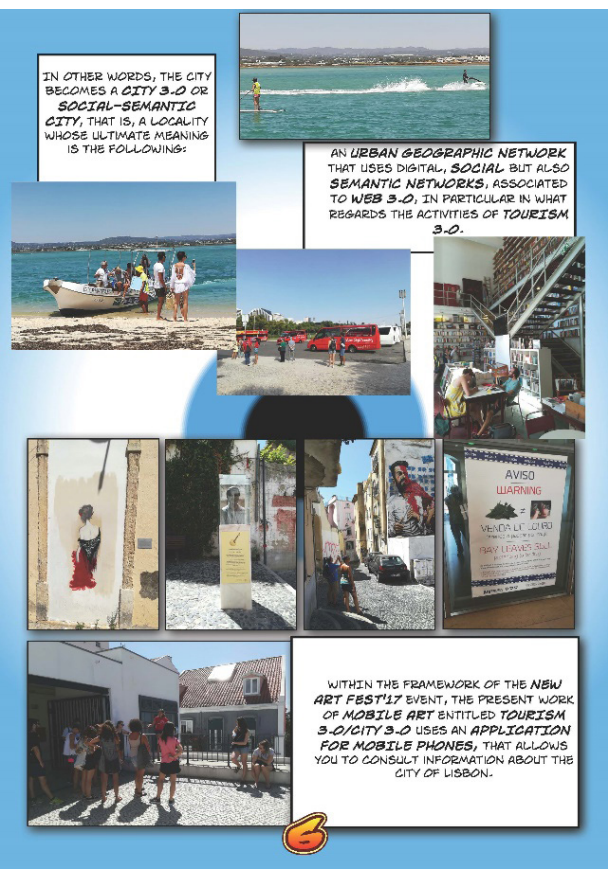

Figura 10: Cidade 3.0, uma rede social-semântica

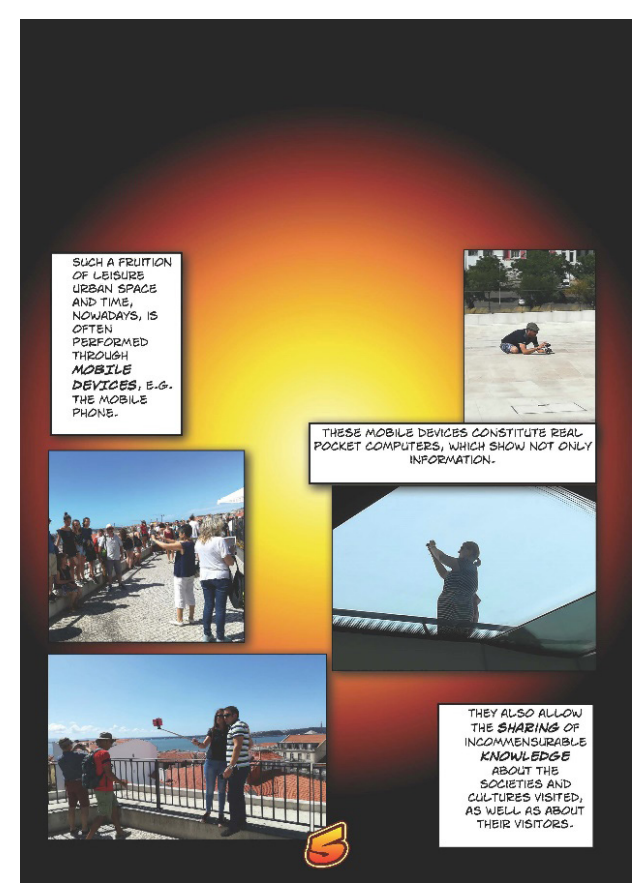

Figura 9: Dispositivos móveis

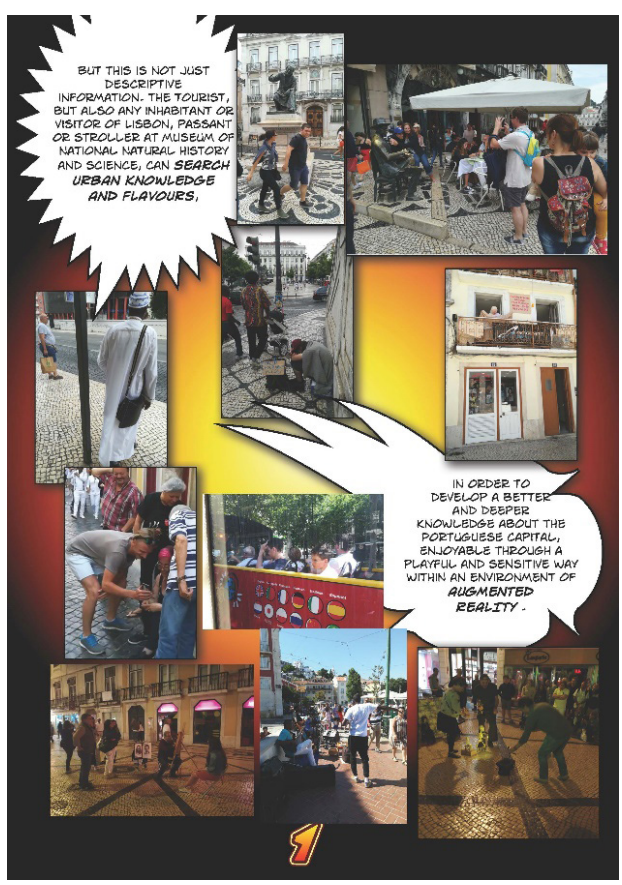

Figura 11: Realidade híbrida no evento NewArtFest'17 
Anexo 3: A técnica inquérito visual-virtual, sobre a Cidade 3.0 / Turismo 3.0

Ficha técnica 2:

Título(s) da obra: Inquérito visual-virtual sobre a Cidade 3.0 / Turismo 3.0

Ano: 2017

Técnica/Medium: Vídeo

Formato: $2 \mathrm{D}$

Dimensão: N.A.

Sinopse: A cidade e o turismo 3.0 (ou 'social-semânticos') fundam-se numa rede de significados sociais e interpretações semânticas singulares acerca do espaço público da vida quotidiana. Esta rede é desenvolvida pelos múltiplos agentes interventores no tecido urbano (habitantes da urbe, turistas, imigrantes, etc.). Trata-se de um processo 'geo-neo-lógico'. Isto é, passa-se num território dado (daí o prefixo 'geo'), num tempo de inovação continua (um ritmo 'neo'), e implicando linguagens diferentes mobilizadas pelos atores urbanos. 'Logos' significa a linguagem ou razão produzidas pelos sujeitos sociais.

Uma questão central é colocada a politicos conhecidos: qual a principal transformação que afeta as cidades contemporâneas e fenómenos relacionados, como o turismo e a imigração?

Equipamento necessário para sua montagem e/ou exibição: Écran de vídeo Necessidades específicas para montagem, transporte ou outros: N.A.

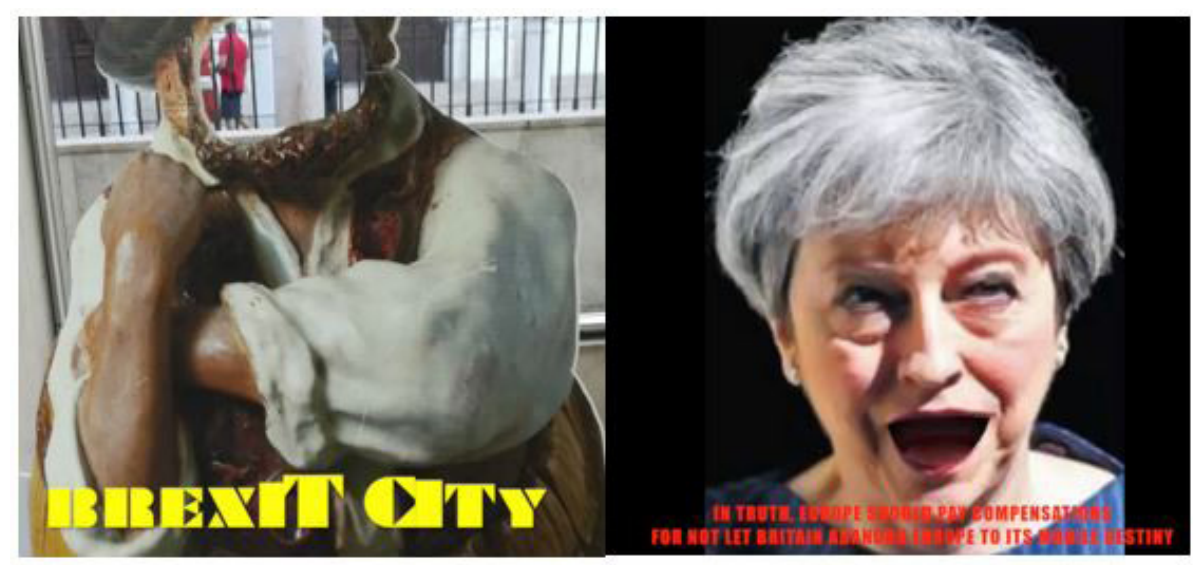

Figura 12

Texto da banda sonora e das legendas do vídeo: Europe countries need more United Kingdom than the inverse, for city mobilities too. In truth, Europe should pay compensations for not let Britain abandon Europe to its mobile destiny 


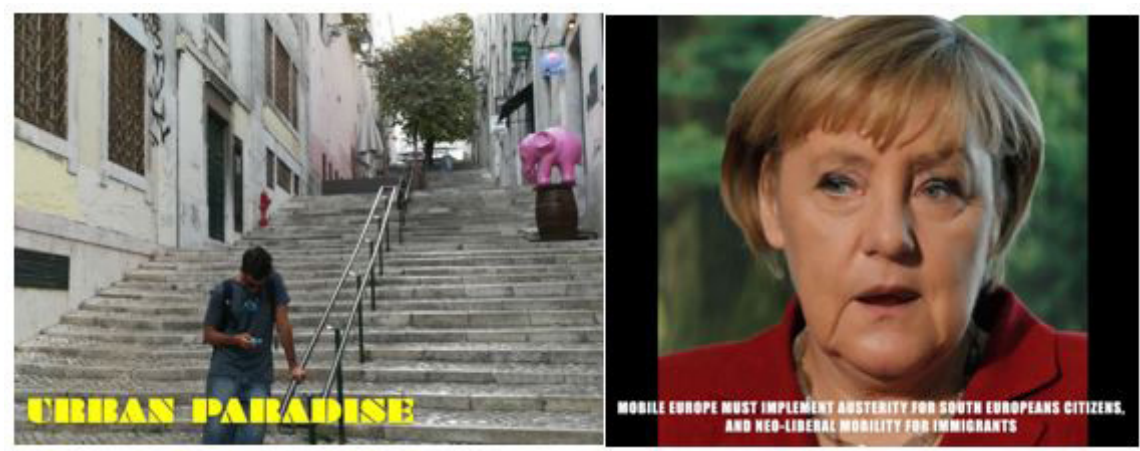

Figura 13

Texto da banda sonora e das legendas do vídeo: Mobile Europe must implement austerity for South European citizens, and neo-liberal mobility for immigrants

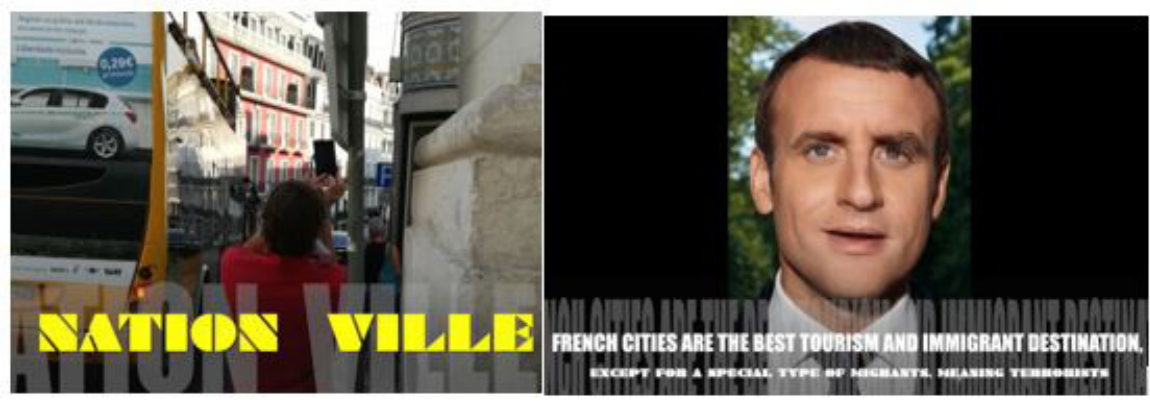

Figura 14

Texto da banda sonora e das legendas do video: French cities are the best tourism and immigrant destination, except for a special type of migrants, meaning terrorist

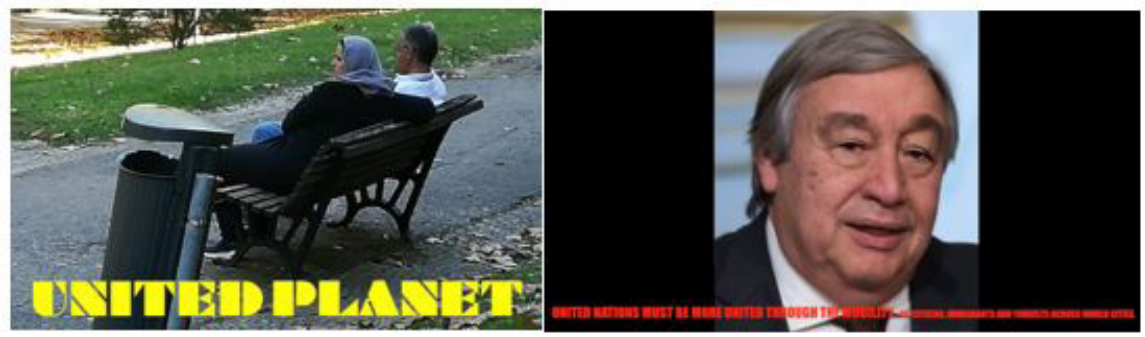

Figura 15

Texto da banda sonora e das legendas do vídeo: United nations must be more united through the mobility of citizens, immigrants and tourists across world cities

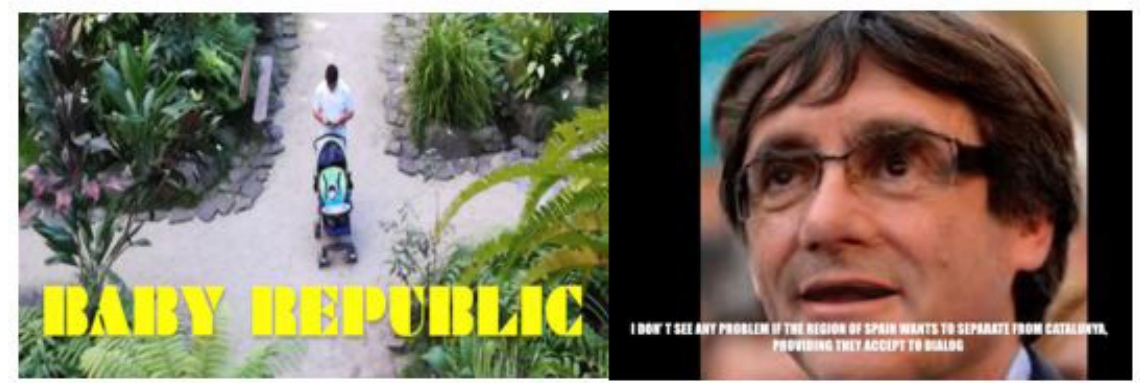

Figura 16

Texto da banda sonora e das legendas do vídeo: I don't see any problem if the region of Spain wants to separate from Catalunya, providing they accept to dialog 


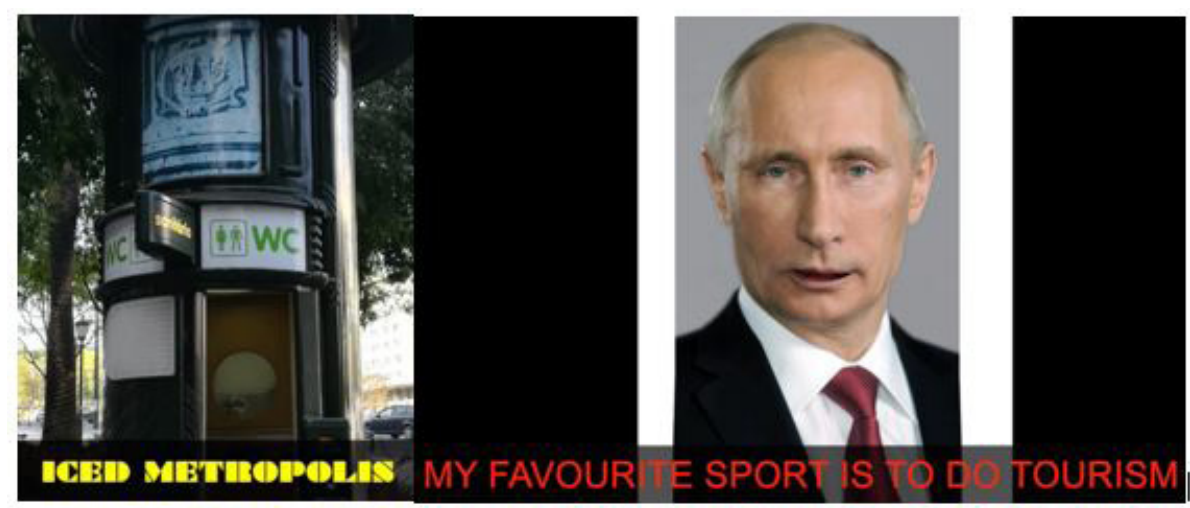

Figura 17

Texto da banda sonora e das legendas do vdeo: My favourite sport is to do tourism in Crimea peninsula and Europe cities. Instead of cars, it is more practical to travel with tanks. Thanks, Europe...

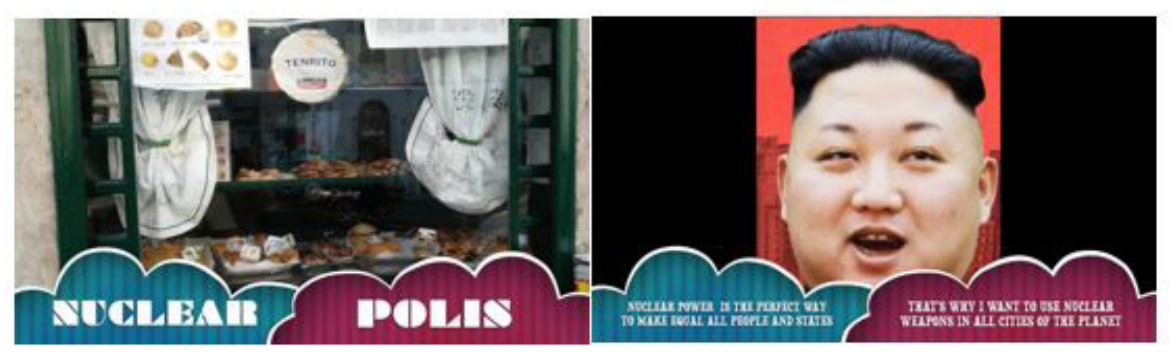

Figura 18

Texto da banda sonora e das legendas do vídeo: Nuclear power is the perfect way to make equal all people and states. That's why i want to use nuclear weapons in all cities of the planet...

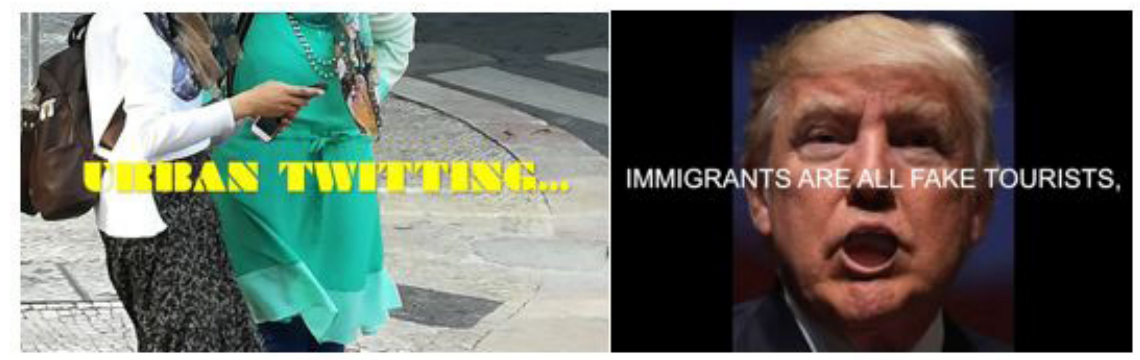

Figura 19

Texto da banda sonora e das legendas do vídeo: Immigrants are all fake tourists, and I am going to fire them all 
Anexo 4: A técnica Galeria Sociológica Virtual, acerca da Cidade 3.0 / Turismo 3.0

Ficha técnica 3:

Título(s) da obra: Galeria Sociológica Virtual sobre a Cidade 3.0 / Turismo 3.0

Ano: 2017

Técnica/Medium: Video, Realidade Aumentada, Realidade Híbrida

Formato: 2D e 3D.

Dimensão: N.A.

Sinopse: esta obra de arte organiza conteúdos e conhecimento sobre Lisboa e o turismo nesta cidade, por meio de textos, imagens e sites sócio-semânticos no interior da Web 3.O. Ao entrar na aplicação, o utilizador pode escolher entre as seguintes links: Home: introdução ao contéudo exposto; About: CV do autor; Gallery: exposição virtual de imagens do Monumento Híbrido; outros links conduzem aos sites social-semânticos Experimental Books e Web 3 Novel, onde se encontram diversos conteúdos sobre a cidade, a cultura e o turismo. O Monumento Híbrido significa uma fusão entre a Torre de Belém em Lisboa e a Torre Eiffel, o que opera uma articulação entre patrimónios culturais diversos. Aqui, é consultável através de um dispositivo de realidade aumentada. O visitante da Galeria Sociológica Virtual experimenta uma inédita e seminal mistura entre as realidades social, virtual, aumentada e mista, um processo que produz a realidade híbrida.

Equipamento necessário para sua montagem e/ou exibição: telemóvel Necessidades específicas para montagem, transporte ou outros: N.A.

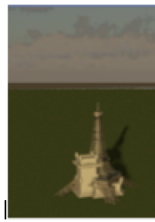

thenew

art fest 1

SOCIOLOGICAL VIRTUAL GALLERY

PEDRO ANDRADE @ 2017

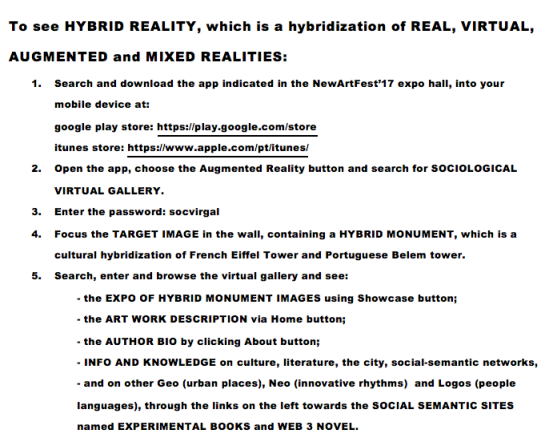

Figura 20 : Folha de sala na exposição 


\section{EIYIBIRID MONOMBNT}

\section{Dedro Andrade () 2001V}

A hybrid monument is a building that operates a fusion of several monuments, in order to celebrate a common cultural heritage. It may help citizens, tourists and migrants, to understand local or global cultural heritage, within a transcultural strategy. Transcultural means the transformation of culture into knowledge, within City 3.0 and Tourism 3.0 contexts.

Belem tower at Lisbon and Eiffel tower at Paris, are two notable cultural and tourist urban icons. Through their fusign, they constitute an example of a hybrid monument.

They aren't exactly twin towers, but they testify a common cultural heritage process. Belem Tower is a ship metaphor, to celebrate the Portuguese discoveries at the XVI century, which initiated the process of globalization. Eiffel Tower is a symbol of another globalization, the industrial revolution around the world at the XIX century. However, their hybridization adverts us that we must both differentiate and connect all world cultures, within a dialogic, democratic and equalitarian basis.

Figura 21: Destinos das hyperlinks: Home: descrição do Monumento Híbrido

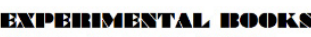

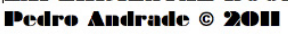

https://sites.google.com/site/livrosexperimentaisenglish/

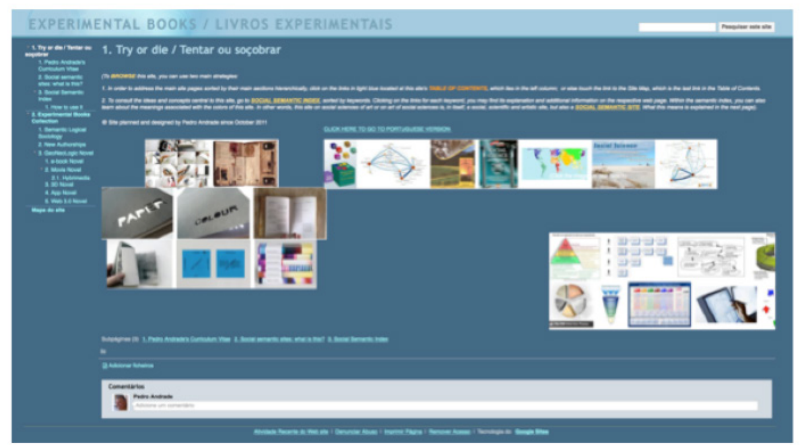

Figura 22: Destinos das hyperlinks: site Experimental Books

WWBIS 83.9 NeDVBL

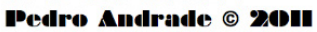

https://sites.google.com/site/weh3novelenglish/

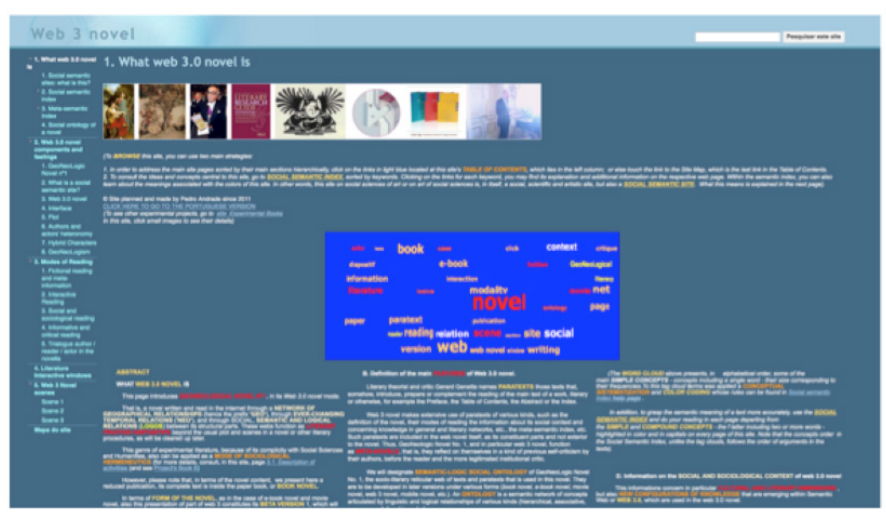

Figura 23: Destinos das hyperlinks: site Web 3.0 Novel 